\title{
Consultants and leadership
}

\section{John Reed \& Peter Hill}

One of the authors was asked recently why he was deliberately being 'politically incorrect' in writing about leadership in mental health services. Leadership, although considered essential to effective working by many professions and commercial organisations, has for years been very much out of favour in the NHS generally, among doctors in particular and, perhaps, among psychiatrists most of all. In part, the roots of such a prejudice lie in the tradition of consensus management which held sway throughout the first three decades of the NHS.

The issue of leadership has been complicated by the rise of non-medical disciplines, ambitious to challenge medical hegemony and establish their own professional autonomy. For some, leadership is tainted with the memories of the evil done by charismatic leaders such as Hitler and Stalin, and the idea of an individual acting as leader offends current egalitarian ideals. One writer (Stewart, 1989) describes the NHS as 'chary' in talking about leadership and quotes a regional manager as saying 'a few years ago I could not have used the word leadership without blushing'.

But the situation in the NHS and the medical profession is changing; the Chief Executive of the NHS (Langlands, 1995, unpublished) has called for better leadership in the mental health service and the Chief Medical Officer (Calman, 1994) for better leadership by doctors. There can be few better informed observers of the medical scene than Richard Smith, the editor of the British Medical Journal. In his view (Smith, 1992/3) "People need leaders. Much of what we [doctors] do that matters we do in groups and groups need leaders", and yet he concludes that doctors have problems with leadership. So far as strategic leadership is concerned doctors "tend to pull down those who try to exert leadership, create institutions that are almost impossible to lead and appoint compromise candidates to leadership positions". And when it comes to operational leadership, in Smith's view 'Doctors are awkward in teams and are inclined to try and dominate rather than lead them. They are too fond of hierarchies and too used to telling people (patients) what to do rather than inspiring or empowering them. They are wary of abandoning control to others - and yet that is at the heart of leadership.'

\section{Leadership in the mental health service}

More than any other group of doctors, psychiatrists should be interested in leadership. The mental health service is still undergoing massive change as it moves from a predominantly institution based service to locally provided care and change needs leadership. Virtually all our work is in teams and teams only work well when led well. How good is leadership in the mental health service? The evidence from many enquiries into disasters in the mental health service suggests that leadership is often poor or lacking.

"...(the consultant) has had an insufficient appreciation of his necessary role as a spur to improvement. It was his duty to give the necessary stimulus and encouragement to his medical colleagues." (Department of Health and Social Security, 1969.)

"...doctors - need professional leadership to promote good practice, develop professional medical skills and drive forward an ethos of excellence in medical care." (Department of Health, 1992.)

"Professional leadership for medical and nursing staff was mentioned by almost all - as being seriously lacking in the mental health services." (South Devon Healthcare NHS Trust, 1994.)

John Reed, FRCPsych, is a Special Adviser to the Department of Health, and has led work on mentally disordered offenders, chairing the joint Department of Health/Home Office review (1990/92); he currently chairs the National Advisory Committee on Mentally Disordered Offenders. Peter Hill, FRCPsych, is Professor of Child and Adolescent Psychiatry at St George's Hospital Medical School, London. He has run management courses for doctors for 15 years, working with the King's Fund College, the NHS Training Authority, the Scottish Health Service Management Group and the British Postgraduate Medical Federation as well as various local commissioners. 


\section{Research into leadership}

Biographers have long been interested in the qualities of famous leaders and early academic work drew upon this to identify personality traits such as intelligence, confidence, dominance, and energy.

But this did little to define how leaders emerge or how they go about leading. Work before and during the Second World War was necessarily associated very closely with military needs but the issue of leadership in the military was, at that time, a relatively straightforward one emphasising motivation and inspiration. Extension to social and managerial systems is more complex. For instance, military leaders have their powers and responsibilities well defined by the system they work in, but in broader society these are not so clear and fundamental questions about the conditions for leadership arise.

\section{Power - an essential element}

Power is crucial since leadership is ineffectual without power. Social power flows from (adapted from French \& Raven, 1959):

(a) legitimacy: a consequence of holding office or a designated position of authority, indicated by a title (doctor, professor) or appointment (consultant, clinical director)

(b) coercion: the power to allocate resources or favours to individuals, or to punish which may be formally recognised in disciplinary rules or arise informally (references for junior medical staff)

(c) personality: charismatic or magnetic personal qualities, often thought (perhaps mistakenly) to be inherent

(d) expertise: on the basis of superior skills, knowledge or experience.

To which it has become commonplace to add:

(e) information: having access to relevant information.

Clearly these attributes could ensure sufficient power for leadership, but even when they are met, some succeed in influencing others to follow their lead and some do not. What else is needed?

\section{Styles of leadership}

In the 1950s, in tune with the times, an emphasis on leader behaviour became prominent, coupled with an understanding that the effectiveness of a particular style of leader behaviour varied with the type of situation or the task involved. This built upon the classic study of Lewin et al (1939) who examined the effect of autocratic, democratic and laissez-faire styles.

Autocratic leadership-directive and unheeding of objections or suggestions from subordinates produced quick results on ordinary assembly tasks but required tight supervision and resulted in poorly motivated and resentful workers who tended to quarrel with each other. Rebellious outbursts or seditious comments occurred. In the absence of the leader, work ceased but while the leader was present, productivity was good.

Laissez-faire leadership, in which the leader did little more than start and stop the process, could produce creative and original results but at the expense of time and with a risk of workers losing interest in the task in hand. Behind the leader's back there was a tendency for workers to give up or become side-tracked into gossip and subsidiary activity. Productivity on assembly tasks was low.

Democratic leadership seemed the best solution. The leader outlined the problem or task and asked for suggestions or views from workers before making a final decision about method. This was then adhered to without the frequent revisions which could occur under laissez-faire leadership. For most laboratory tasks facing a small group it was the most successful style of leadership in terms of productivity and worker satisfaction. Interactions with the leader were usually positive and task-related. Workers were cooperative with each other. In the absence of the leader, the workers usually continued with the task. Democratic leadership became the preferred general leadership style although the experimental work on which it was based tended to involve rather boring tasks and in real-life situations there was a suspicion that democratic leaders were successful, at least in part, because they were more intelligent than their autocratic colleagues (Sayles, 1966). (Child and adolescent psychiatrists will note the close parallels with Baumrind's (1967) classification of parenting styles and, indeed, her findings with respect to their impact on children.)

Although the zeitgeist of the post-war period favoured the adoption of democratic leadership styles it became clear that, when there was a high level of urgency and the task was structured, autocratic leaders won hands down. Conversely, when originality and creativity were needed and there was ample time, a laissez-faire style could be particularly successful. Clearly there was an interaction between leadership style and type of task. 
This realisation - that it was necessary to examine leadership style in relation to the type of task - led to enquiry into whether leaders could change their style according to the task in hand. Ideally a competent leader should have a repertoire of leadership styles and deploy them appropriately according to the task facing the group. Indeed, if they did not amend their style to meet the demands of the situation the assigned leader might be replaced from within the group by a leader whose style was more appropriate, the so-called emergent leaders who achieve authority from within the group rather than being imposed from outside. Generally speaking, it was found that the skills of emergent leaders matched the demands of the task better than those of the appointed leader. They had better interpersonal skills when a cohesive approach was required and were more decisive when the task facing the group required urgent action. But it proved difficult to show that leaders did or could change their style to match different situations and to explain why leaders were often slow to shift their mode of leadership.

Since situation can influence effectiveness of leadership style, some measure of the situation is required. Vroom \& Jago (1988) listed up to 12 situation variables, each rated on a five point scale, and related this to a five point measure on the autocratic-democratic dimension. Although methodologically respectable, it is not clear whether the results are any more than common sense. Where workers need motivation, the leader lacks information, or the task is unstructured, a participative approach is better. If workers do not share a common goal, direction is required.

The attitudes of leaders to their workers became a focus of interest. McGregor (1960) suggested that there were two stereotypes. One believed workers to dislike work, be inherently lazy, unambitious and fond of job security. It followed that to this stereotype coercion and control were crucial leadership activities. The second stereotype thought employees viewed work as a natural activity, sought responsibility and exercised selfdirection if committed to the agreed objectives. Combining this attitudinal perspective with the need to alter leadership behaviour according to task, a two-dimensional plot results, as in Fig. 1 (Tannenbaum \& Schmidt, 1973). On one axis is a continuum of worker participation in decisions about the task ranging from autocratic to democratic so that the leader respectively: tells, sells to, consults or delegates to the workers, decisions about the task. On the other axis is the degree of job structure: the extent to which roles and activities and controls are defined in ensuring the group achieves its primary task.

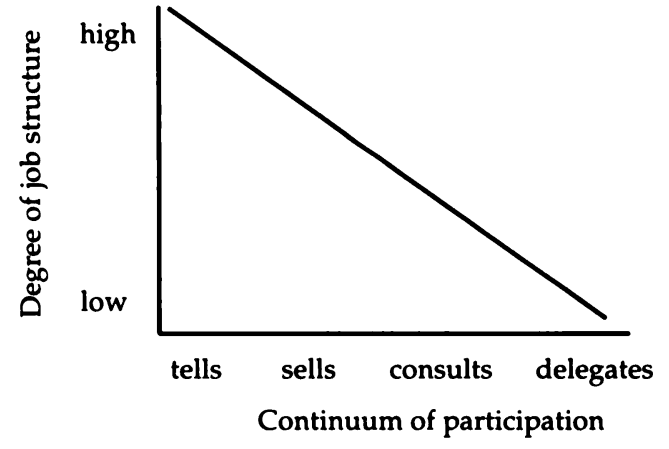

Fig. 1 I eadership behaviour and job structure

By the late 1960s a consensus emerged labelling the two dimensions of leadership:

(a) structure - the extent to which a leader defines tasks and directs worker activity

(b) consideration - the extent to which he enjoys the trust, respect and emotional consideration of workers.

Leaders who were high on structure were ineffective unless also high on consideration (Blake \& Mouton, 1964). But leaders' self-completion of questionnaires did not agree well with workers' perceptions, the latter tending to categorise rather than compare, so that leaders were seen as either person-orientated or task-centred, not both (Weissenburg \& Kavanagh, 1972).

Situational leadership theory (SLT) examines the interaction of these two dimensions of leadership (structure and consideration) with the level of experience or maturity of workers. SLT's more extreme advocates have argued that if tasks are sufficiently interesting, no leadership is required for mature and experienced workers. Although this model predicts that workers with high levels of maturity would need very little supervision and personal support, this was found not to be so in a study of teachers' satisfaction and performance (Vecchio, 1987).

Probably the most discussed work on leadership in the late 1960s and '70s was that of Fiedler. This involved a more complex formulation based on both fieldwork and laboratory exercises. At its core was the least preferred co-worker (LPC) measure (Fiedler, 1967; Fiedler \& Garcia, 1987). This is the extent to which a leader views their least favourite worker positively and therefore clearly has a lot in common with consideration and person-orientation. It is possible to enter LPC scores into a matrix against task structure, the position power and the trust workers have in their leader. The predictions bear up well in the laboratory but less well in field studies (Peters et al, 1985). Nevertheless, the theory 
has received a great deal of attention and represents a fairly robust method of exploring situational variables even if it is not very user-friendly for aspirant leaders.

By the early 1980s leadership studies were wilting. Questionnaire studies tended to give inconsistent results and the generalisability of laboratory work to the workplace was questionable, particularly as much early inquiry had relied on studying groups of children. But the emergence of the growth economies of Pacific Rim countries began to threaten American businesses and the challenge of increasing European integration was doing the same to British industries. In an atmosphere of continuing change and challenge, leadership became worthy of study again.

\section{Charisma}

Charisma as a leadership quality is one subject that has again become a respectable area of study although it is often called transformational style (visionary and concerned with maintaining a positive image in the minds of their followers), as distinguished from transactional style which is performance orientated. Extending Bass (1985), charismatic (transformational) leaders:

(a) transmit a sense of mission and pride through their self-confidence, optimism and excellent communication skills. They inspire others with their vision and values

(b) are consistent in their values and stick to their goals

(c) treat each follower/worker as an individual and are concerned with their personal development

(d) are decisive although they stimulate individual thinking and reasoning before decisions are made.

On the other hand transactional leaders:

(e) provide rewards contingent upon adequate performance

(f) tolerate existing work patterns provided that targets are met.

It probably goes without saying that effective leadership requires a combination of transformational and transactional styles with the ability to bring the most relevant components of each into play when a particular task or context demands them.

Meindl et al (1985) have argued on the basis of both survey and laboratory material that our belief in the need for leadership is at its height when things are going either very well or very badly. In the current climate of change and uncertainty in the commercial world, leadership is perceived as a major issue (Kotter, 1994). A similar climate of rapid change and uncertainty is prevalent in the mental health service and so talk of leadership is very apposite.

\section{What sort of person makes a good leader?}

Kotter (1994) examined leadership in American industry and suggested the following requirements for leadership (paraphrased):

(a) breadth of relevant knowledge and competence at skills prized within the organisation

(b) good interpersonal skills (empathy, persuasiveness, friendliness)

(c) solid interpersonal relationships in the organisation

(d) justified credibility

(e) keen analytical skills and good judgement

(f) high integrity

(g) high energy level

(h) high power and achievement needs backed by self-confidence.

Organisations that succeed in adapting to change, Kotter argues, encourage the development of these abilities and recruit with them in mind. A vision of what is needed or what direction to take is essential. Creating an agenda for change and establishing a strong implementation group are the key activities. A vision that is coupled with an intelligent implementation strategy can be realised if there is a core group of loyal and committed individuals who can be motivated and made to work as a team.

\section{Can leadership be taught and learnt?}

The techniques of transactional style are eminently teachable. Indeed, they are the very stuff of management courses; appraising subordinates and monitoring their work, motivating them and setting targets. They can also be evaluated. For instance, Komaki (1986) was able to show that the difference between highly effective and marginally effective leaders hinged upon whether they monitored their staff's activity. On the other hand, whether they used rewards contingently according to operant principles seemed to make much less impact. This may be because skilled staff need relatively little differential material reward to motivate them or because the ability to use 
contingent reward depends on monitoring in the first place. Both monitoring and reward seem necessary regardless of the relative contribution of each. Setting specific, challenging goals and providing feedback on the basis of monitoring contributes further (Locke \& Latham, 1990). It is much less clear that transformational leadership is teachable (although it may be learnable). On first principles it might be that modelling is the most effective method and certainly personal example is an attribute of the effective leader (Keegan, 1988).

\section{Team leadership in practice}

Working in a team is central to medical practice and nearly all psychiatric practice involves teamwork. But team working is not a single skill. It is apparent, following the experimental work of Belbin (1981), that effective teams contain individuals with a variety of roles. Homogeneous teams are relatively ineffective. Occupying the role described by Belbin as a 'teamworker' means demonstrating little initiative but much cooperation with others. But effective teams are not composed solely of teamworkers. As the report of the enquiry into the care of Andrew Robinson (Blom-Cooper et al, 1995) pointed out; "joining with other disciplines in a common endeavour does not mean that professionals abandon their discipline for a generic soup". Within the roles described by Belbin for teamworkers are figures such as 'chair' and 'shaper' who drive, motivate, inspire and coordinate by the exercise of power. Teams do not function well without such roles. In other words, optimally performing teams need leaders, not a clone of teamworkers.

The General Medical Council (GMC) in Tomorrow's Doctors (1993) urges doctors to learn how to work in teams and set out "the standards of competence, care and conduct" required of doctors. In 1995 the GMC advised 'You are expected to work constructively within such teams and to respect the skills and contributions of colleagues... If you are leading a team, you must do your best to make sure that the whole team understands the need to provide a polite and effective service'.

\section{Psychiatrists and team leadership}

Leadership is needed to achieve the three interrelated objectives of team working (Fig. 2): achieving the task, developing the individual members of the team and maintaining the team

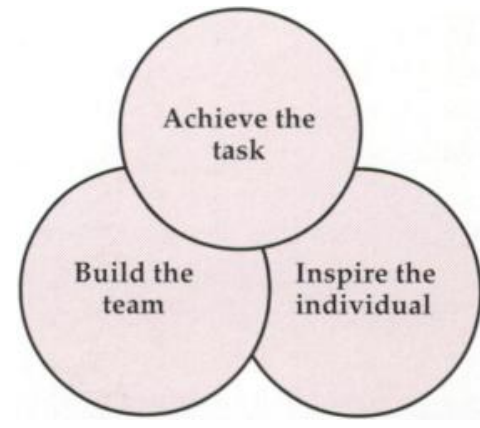

Fig. 2 The three objectives of team working

(Adair, 1988). To ensure this team leaders must have authority which, as Adair has pointed out, flows from: position - one's title or appointment; knowledge - one's professional expertise; personal attributes - one's personality and way of working.

In the past, leadership in the mental health service was determined largely by position as consultant psychiatrist or medical superintendent; at times this worked well, very often it did not. But, rightly, it is no longer acceptable to say "I am a consultant psychiatrist, therefore I must lead the multi-disciplinary team". There is no rule saying that the leader, either operationally or strategically, has to be a doctor as opposed to a nurse, a manager or other health professional, though there may be strong arguments in favour of the doctor leading. Whatever their professional background the person who leads must be the person best able to lead.

Psychiatrists should be well placed when it comes to authority and the ability to lead, they have the authority of position which in some cases is enshrined in legislation as the 'responsible medical officer' (and from April 1996 as the 'community responsible medical officer') and the authority of knowledge of human psychological function and dysfunction. Where psychiatrists may be less well placed is in understanding the nature of leadership and the personal attributes that make an effective leader. These have been summarised by Adair (1988) (Box 1). One other attribute of a successful leader can be added: personal example - being known for sharing the problems facing the team and always being available when advice and support is needed (Keegan, 1988).

In short, position and medical knowledge alone are not enough to enable you to lead a team successfully, they must be coupled with knowledge of leadership and team working and the appropriate personal attributes.

\section{Learning to be a better leader}

Perhaps the most important first step in learning 
Box 1. A good leader needs to show:

Initiative - understand problems and find solutions

Perseverance - getting things done even under difficulties

Integrity - creating trust in the group

Tact - and consideration for team members' feelings

Compassion - dealing with team members problems

Humour - to see the team through bad times

Humility - remember you are not God, just the team leader.

to be a better leader is one that you have already taken by reading this article. You have now thought about what leadership involves and about how your work, and that of the team you work in, could be made better and easier by effective leadership. Many of the topics covered in this article are bread and butter to management training courses and there is no reason to doubt that such teaching could be translated to address the needs of multidisciplinary team working. The College has developed training material and runs regular workshops on clinical leadership.

Leaders by definition have followers; do you know what your team thinks about you? If you do not you should find out. Many successful organisations regularly use team feedback as a way of helping their leaders to develop. One of the authors has run management courses for senior registrars over the last 15 years, part of which includes a discussion session on 'good and bad bosses'. Participants are encouraged to tell suitably anonymised anecdotes about good and bad bosses they have known. The same four components always emerge from senior registrar anecdotes in this session. Good bosses are organised (so are consistent and available), are clinically competent, have integrity and a genuine interest in their trainees. It is this last point which results in most nods around the table.

\section{How we can improve the situation?}

Psychiatrists should not be deterred by political correctness from discussing the benefits of good leadership; health is too important an issue. One simple thing consultants can do is to ensure that they exhibit a high level of competence and current knowledge honed by continuing professional development and involvement in audit. Adair
(1988), using a number of illustrations, makes the point that competence is crucial for effective leadership. If competent, a leader can demonstrate and lead by example so that juniors can learn skills which enable them to take on tasks. The old adage is that leaders need to know the trade, not the tricks of the trade.

We can train transactional, task-centred leadership methods and we can emphasise the need for consultants to have a repertoire of leadership styles which can be deployed to suit the occasion, according to models such as that of Tannenbaum \& Schmidt (see above). At the same time we can encourage consultants to adopt the style of transformational leadership. Where leadership and leadership potential is lacking, recruitment may be a way of bringing leadership into an organisation. It may be appropriate for appointment committees to consider leadership - proven or potential among candidates.

\section{Conclusion}

Do we teach, encourage or select for leadership? In practice we can do all three by teaching basic management skills, promoting clinical competence through continuing professional development and selecting psychiatrists at interview for more than direct patient care skills. Whatever else we do we must act. If we do not we will find ourselves led and we may not approve of the direction taken.

\section{References}

Adair, J. (1988) Effective Leadership. London: Pan Books.

Bass, B. M. (1985) Leadership and Performance: Beyond Expectations. New York: Free Press.

Baumrind, D. (1967) Child care practices anteceding three patterns of preschool behaviour. Genetic Psychology Monographs, 75, 43-88.

Belbin, R. M. (1981) Management Teams: Why They Succeed or Fail. Chichester: John Wiley.

Blake, R. R. \& Mouton, J. S. (1964) The Managerial Grid. Texas: Gulf Publishing.

Blom-Cooper, L., Halley, H. \& Murphy, E. (1995) The Falling Shadow: One Patient's Mental Health Care 1978-1993. London: Duckworth.

Calman, K. (1994) The profession of medicine. British Medical Journal, 309, 1140-1143.

Department of Health (1992) Report of the Committee of Inquiry into Complaints about Ashworth Hospital. Cmnd 2928-1. London: HMSO.

Department of Health and Social Security (1969) Report of the Committee of Inquiry into Allegations of ill-treatment of Patients and other irregularities at the Ely Hospital, Cardiff. CMND 3975. London: HMSO.

Fiedler, F. E. (1967) A Theory of Leadership Effectiveness. New York: McGraw-Hill.

- \& Garcia, J. E. (1987) New Approaches to Effective Leadership: Cognitive Resources and Organizational Performance. New York: John Wiley. 
French, J. R. P. \& Raven, B. (1959) The basis of social power. In Studies in Social Power (ed. D. Cartwright). Michigan: Institute for Social Research.

General Medical Council (1993) Tomorrow's Doctors: Recommendations on Undergraduate Medical Education. London: GMC.

- (1995) Good medical practice. In The Duties of a Doctor, p. 8. London: GMC.

Keegan, J. (1988) The Mask of Command. London: Penguin.

Komaki, J. L. (1986) Toward effective supervision. Journal of Applied Psychology, 71, 270-279.

Kotter, J. P. (1994) The Leadership Factor. London: Collier Macmillan.

Lewin, K., Lippet, R. \& White, R. (1939) Patterns of aggressive behaviour in experimentally created 'social climates'. Journal of Social Psychology, 4, 19-31.

Locke, E. A. \& Latham, G. P. (1990) Work motivation and satisfaction: light at the end of the tunnel. Psychological Science, 1, 240-246.

McGregor, D. (1960) The Human Side of Enterprise. New York: McGraw-Hill.

Meindl, J. R., Ehrlich, S. B. \& Dukerich, J. M. (1985) The romance of leadership. Administrative Science Quarterly, 30, 78-102.

Peters, L. H., Hartke, D. D. \& Pohlmann, J. T. (1985) Fiedler's contingency theory of leadership: an application of the metaanalysis procedures of Schmidt and Hunter. Psychological Bulletin, 97, 274-285.

Sayles, L. R. (1979) Leadership: What Effective Managers Do...and How They Do It. New York: McGraw-Hill.

Smith, R. (1992/93) Doctors and leadership: oil and water? Trevor Lloyd Hughes Memorial Lecture Liverpool Medical Institution Transactions and Report.

South Devon Healthcare NHS Trust (1994) Report of the Review of the Mental Health Services Of the South Devon Healthcare Trust.

Stewart, R. (1989) Leading in the NHS: A Practical Guide. London: Macmillan.

Tannenbaum, R. \& Schmidt, W. H. (1973) How to choose a leadership pattern - retrospective commentary. Harvard Business Review, May-June.

Vecchio, R. P. (1987) Situational leadership theory: an examination of a prescriptive theory. Journal of Applied Psychology, 72, 444-451.

Vroom, V. H. \& Jago, A. G. (1988) The New Leadership: Managing Participation in Organizations. Englewood Cliffs, NJ: PrenticeHall.

Weissenburg, P. \& Kavanagh, M. J. (1972) The independence of initiating structure and consideration: A review of the evidence. Personnel Psychology, 25, 119-130.

\section{Multiple choice questions}

1. Sources of authority for leadership include:
a Age
b Occupation or appointment
c Technical knowledge
d Gender
e Personality and leadership skills.

2. Effective leaders:

a develop the skills of their team

b only offer support when team members ask for it

c agree priorities and allocate tasks with the team

d are readily available

e rarely have time for continuing professional development.

3. Teamworking skills:

a can not be taught formally

b are well developed by undergraduate medical education

c need up-dating from time to time

d improve patient care

e have often been found lacking in postincident inquiries.

4. Transactional leadership:

a places teamworkers in the position of a child compared with an adult

b is orientated towards team performance

c relies on personal charisma

d monitors or rewards subordinates' activities

e nearly always requires very rapid decision making.

5. When taking up leadership of a team:

a it is necessary to consider what kind of task faces the team

b discovering the personal needs of team members is a distraction

c it is best to issue directive instructions promptly, regardless of the situation

d seeking feedback from team members about your competence as a leader reduces your social power

e sharing your vision of how things will develop is an effective leadership activity.

MCQ answers

$\begin{array}{llllllllll}\text { 1 } & & \text { 2 } & & 3 & & 4 & & 5 & \\ \text { a } & \text { F } & \text { a } & \text { T } & \text { a } & \text { F } & \text { a } & \text { F } & \text { a } & \text { T } \\ \text { b } & \text { T } & \text { b } & \text { F } & \text { b } & \text { F } & \text { b } & \text { T } & \text { b } & \text { F } \\ \text { c } & \text { T } & \text { c } & \text { T } & \text { c } & \text { T } & \text { c } & \text { F } & \text { c } & \text { F } \\ \text { d } & \text { F } & \text { d } & \text { T } & \text { d } & \text { T } & \text { d } & \text { T } & \text { d } & \text { T } \\ \text { e } & \text { T } & \text { e } & \text { F } & \text { e } & \text { T } & \text { e } & \text { F } & \text { e } & \text { T }\end{array}$

